\title{
Performance evaluation of mahua stamen remover
}

\author{
S. K. Pandey, V. Choubey, P. K. Mishra and S. Pandey
}

Received : 25.07.2019; Revised : 19.08.2019; Accepted : 05.09.2019

See end of the Paper for authors' affiliation

Correspondence to :

S. K. Pandey

Department of Agricultural Engineering, Birsa Agricultural University, Kanke, Ranchi (Jharkhand) India Email : sushil.pandey999@ gmail.com
ABSTRACT : Mahua stamen remover was evaluated for its performance. It was tested at four moisture levels $(11.9,13.17,15.64$ and $17.66 \%$ d.b. $)$ and three feed rates $(15,21,27 \mathrm{~kg} / \mathrm{h})$. The stamen removal efficiency and whole flower recovery were determined to optimize feed rate and moisture content of mahua flower for better performance of the machine. The present study revealed that the optimum flower moisture content and feed rate were found to be 13.17 per cent and $15 \mathrm{~kg} /$ h, respectively with stamen removal efficiency of 88.23 per cent and whole flower recovery of 81.2 per cent.

- KEY WORDS : Mahua stamen remover, Stamen removing efficiency, Whole flower recovery ans deseeder

- HOW TO CITE THIS PAPER : Pandey, S.K., Choubey, V., Mishra, P.K. and Pandey, S. (2019). Performance evaluation of mahua stamen remover. Internat. J. Agric. Engg., 12(2) : 199-202, DOI: 10.15740/HAS/IJAE/12.2/199-202. Copyright@2019: Hind Agri-Horticultural Society. 